\title{
The distribution of multiple sclerosis in the United Kingdom
}

\author{
RJ SWINGLER, DAS COMPSTON \\ From the Section of Neurology, University of Wales College of Medicine, Cardiff, UK
}

SUMMARY Parts of the United Kingdom have the highest incidence, prevalence and mortality rates for multiple sclerosis in the world. Although methods of ascertainment are not standardised, regional differences and changes with time are present for each of these statistics. Mortality has declined, whereas prevalence and hospital discharge rates have increased owing in part to the improved survival but also to better case ascertainment. The gradient in prevalence seen between Southern England $\left(63 / 10^{5}\right)$, Northern England and Northern Ireland $\left(76-79 / 10^{5}\right)$, Wales $\left(c .113 / 10^{5}\right)$, North-East Scotland $\left(155 / 10^{5}\right)$ and the Orkneys $\left(258 / 10^{5}\right)$ can in part be attributed to varying methods of ascertainment but correlates with regional differences in the frequency of HLADR2 in normal individuals (21-50\%). However no HLA-DR2 association is observed in parts of Scotland, where the prevalence is the highest in the United Kingdom, because HLA-DR2 and linked genes occur in up to $50 \%$ of the normal population from these areas. If the aetiology of multiple sclerosis is multifactorial the frequency of the disease will increase where susceptibility genes are common because the probability of concurrence of the remaining critical events is high; conversely when each aetiological agent is infrequent the chance of them all occurring in the same individual and therefore incidence of the disease are both lower. The fall in incidence observed in the Orkney Islands, possibly reflecting decline in an exogenous agent interacting with susceptibility factors, is consistent with this multifactorial hypothesis.

Differences in the distribution of multiple sclerosis have been studied in the hope that temporal, geographical and individual variations may provide clues to the aetiology. The World can be categorised into low, medium and high prevalence zones with increasing distance from the equator but frequency also varies in some regions of similar latitude and between racial groups living in the same area. ${ }^{1}$ These and other epidemiological observations have established the infective and genetic theories for the cause of multiple sclerosis but it is difficult to test these hypotheses in more detail using epidemiological methods because world-wide variations in methodology and other factors prevent detailed comparison between countries. Investigations within particular regions are less likely to be confounded in this way.

Variations in the number of new cases in an at-risk

Address for reprint requests: Dr DAS Compston, Department of Neurology, University of Wales College of Medicine, Heath Park, Cardiff CF4 4XN, Wales, UK.

Received 5 November 1985.

Accepted 5 December 1985 population per year (incidence) provide the best measure of any change in the influence of aetiological factors. Unfortunately the incidence of multiple sclerosis is difficult to measure since the disease is rare, of long duration and insidious onset. However other statistics which depend on incidence may usefully be examined especially point prevalence, which varies with incidence and mean duration of the disease. Mortality rate, which approximates to incidence assuming near complete certification of diagnosed cases, can be used in areas which have not been surveyed. Hospital discharge rates should reflect prevalence but are biased by variations in availability of local resources, interest and admission policies. Lastly, estimates of prevalence and incidence of multiple sclerosis recorded in surveys of general practice should produce better case ascertainment than hospital-based studies.

We have reviewed all the available incidence, prevalence, mortality and morbidity statistics for multiple sclerosis relating to the United Kingdom from 1921. The geographical trends can in part be accounted for by methodological factors but the distribution of the disease correlates better with regional variations in the frequency of HLA-DR2 in normal individuals 
Table Surveys of multiple sclerosis in the United Kingdom since 1931

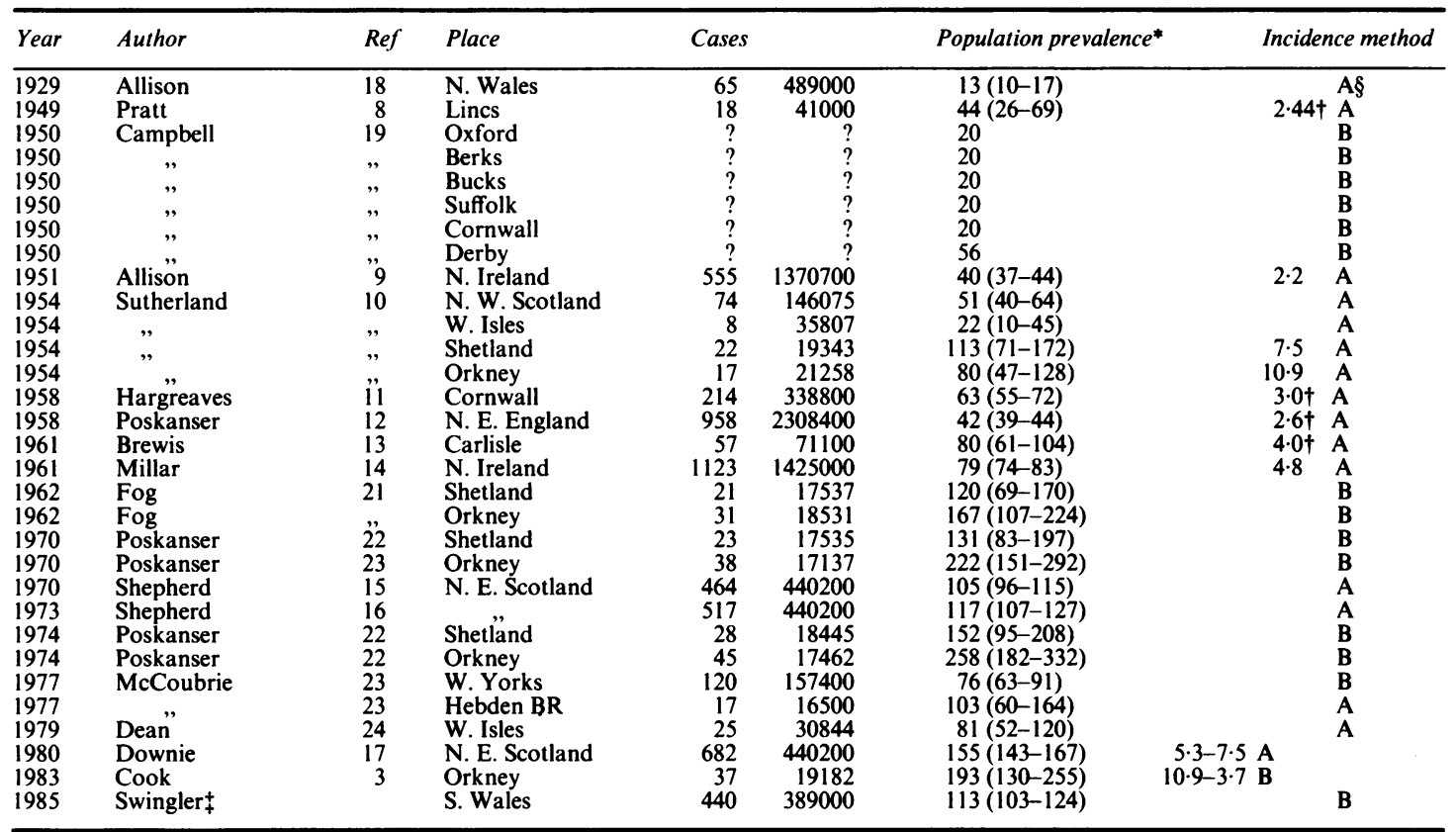

Cases of possible multiple sclerosis are not included.

*95\% confidence limits calculated according to method of Kurtzke ${ }^{1}$

tCalculated from prevalence and duration of disease.

In preparation.

$\S \mathrm{Method} \mathrm{A}=$ reviewed cases, near complete ascertainment, compatible in methodology and diagnostic criteria. Method B = unreviewed cases or less comparable methodology.

than other factors which might influence the distribution of multiple sclerosis. ${ }^{2}$ But genetic factors alone cannot account for the trends with time, especially the decline in incidence in some areas, ${ }^{3}$ indicating that the aetiology of the disease is multifactorial.

\section{Methods}

\section{Incidence and prevalence}

All incidence and prevalence surveys published since 1931 were reviewed; the methods differed considerably between individual studies (table). Where incidence rates were not provided we have derived a figure from the quoted prevalence and mean duration of disease. Prevalence rates for cases of definite and probable multiple sclerosis have been used where possible but some studies only provide an overall estimate and patients with suspected multiple sclerosis may be included.

In view of the rarity of the disease and the absence of a specific diagnostic test, it has rarely been possible clinically to screen random samples of a given population so that case finding techniques have been used, relying initially on postal questionnaires to medical practitioners, searches of local medical records and examination of hospital diagnostic indices or membership of local multiple sclerosis societies; more recently computer-based records from the Hospital Activity Analysis and departmental or general practice morbidity registers have been used.

\section{Mortality}

Mortality returns for multiple sclerosis as the underlying cause of death were obtained from publications of the Registrars General relating to Scotland, Northern Ireland, Wales and the Regional Health Authorities (RHAs) of England for the period 1976-80, the most recent available. Standardised Mortality Ratios (SMRs) were then calculated by comparing the observed number of deaths in each of these regions with the number expected based on the figure for England and Wales between 1951-75 which is given an arbitrary SMR of 100 . SMRs for other quinquennia have previously been calculated for Scotland, Northern Ireland and England and Wales as a whole using the same method. ${ }^{4} \mathrm{We}$ have derived the ratios separately for Wales in 5 year intervals between 1961-80. Ratios for the United Kingdom have been plotted to detect trends with time. In order to distinguish a cohort from a period effect age-specific mortality rates for multiple sclerosis in England \& Wales for each year from 1968-78 were examined separately for males and females by standardisation to mid-year population estimates for each of these years but insufficient data was available for mathematical analysis. 


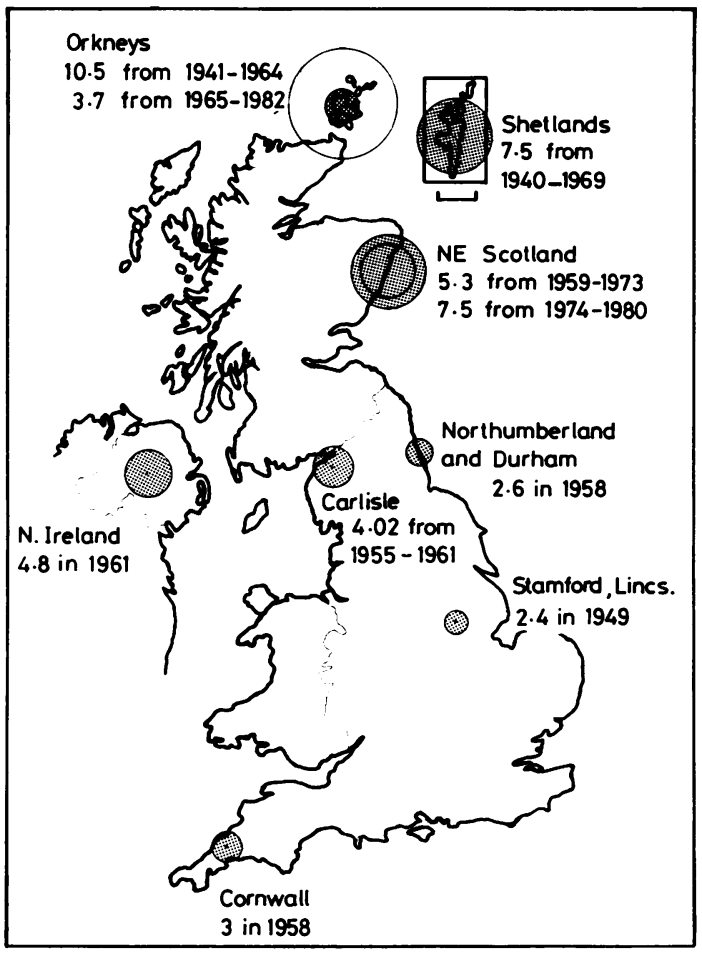

Fig 1 The incidence of multiple sclerosis in the United Kingdom. The diameter of the circles is proportional to the local rate. In areas surveyed more than once the hatched areas represent the most recent estimate.

\section{Morbidity}

Hospital discharge rates for multiple sclerosis were obtained from the Hospital In-Patient Enquiries (HIPE) for Scotland, England and Wales. The HIPE is processed by the Office of Population Censuses and Surveys and collects details for every 10th patient discharged from a general hospital in England \& Wales. The mean discharge rates for 1976-80 from these areas were determined and used to derive a standard rate (that is 1.00 ) using population estimates for 1978 . Discharge rates for the 5 year period 1976-80 in Scotland, Wales and the Regional Health Authorities of England were then expressed as a ratio of this mean. Discharge rates for multiple sclerosis as principal condition for the whole of England and Wales during the period 1968-78 were also obtained from HIPE to detect trends with time.

\section{General practice morbidity statistics}

National Morbidity Surveys in which participating General Practitioners informed the Office of Population Censuses and Surveys about the nature of patient consultations were conducted in England and Wales in 1955-56, ${ }^{5} 1970-76^{6}$ and 1981-82 (unpublished). They were conducted jointly by the Royal College of General Practitioners, Office of Population Censuses \& Surveys and the Department of Health \& Social Security. The statistics can be used to provide national esti-

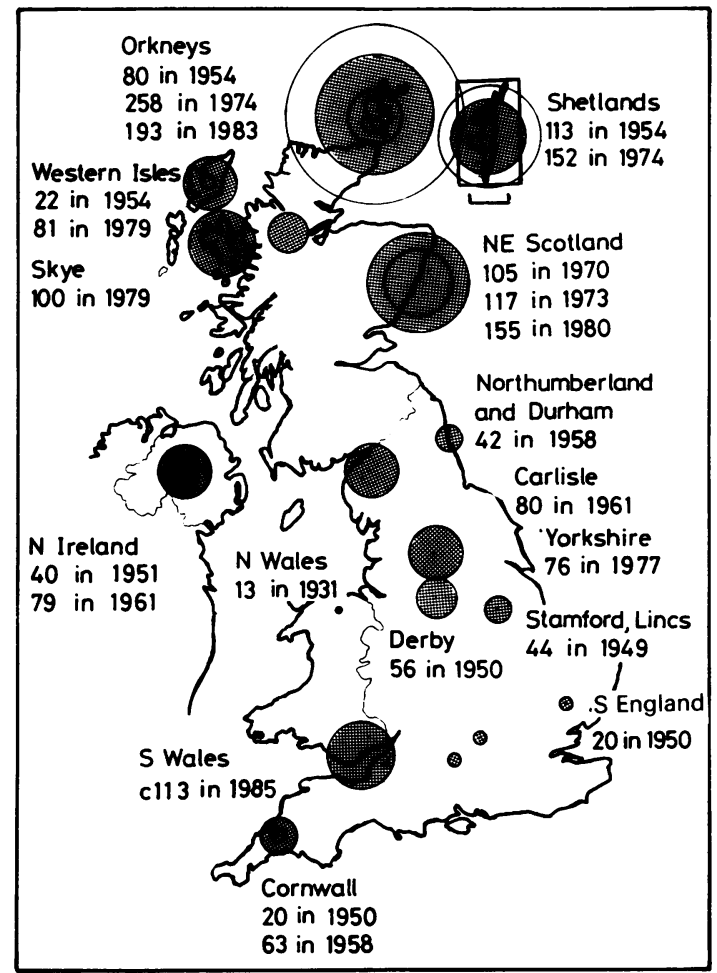

Fig 2 The prevalence of multiple sclerosis in the United Kingdom. The diameter of the circles is proportional to the local rate. In areas surveyed more than once the hatched areas represent the most recent estimate.

mates of incidence and prevalence for each disease studied. Patient consultation rates for multiple sclerosis were obtained from both published surveys which provide national and/or regional rates.

\section{HLA studies}

A prevalence rate for each area was identified and compared with the frequency of HLA-DR2 in normal controls, and patients with multiple sclerosis where available, obtained either from published results or a local tissue typing laboratory by personal communications. The 1974 prevalence rate was used for the Orkneys because this was obtained at the same time HLA typing was carried out. ${ }^{7}$ We have used the frequency of the antigen B-group 4 in normal Orcadians and this locally designated antigen may not be identical to HLA-DR2.

\section{Statistical methods}

Spearmanns rank correlation test was used to test the strength and direction of national trends in mortality \& morbidity over time and chi-squared tests were performed to examine the significance of regional variations. A regression line was fitted to the HLA-DR2/prevalence data but there is insufficient information from surveys of the United Kingdom to extrapolate to areas of low prevalence and HLA- 


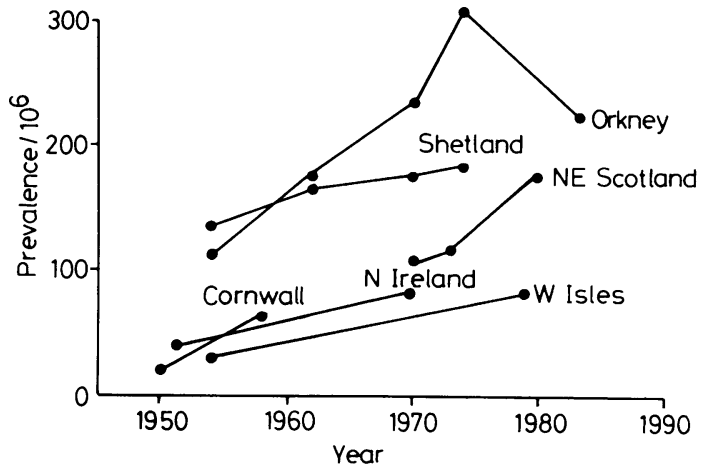

Fig 3 Serial estimations of the prevalence of multiple sclerosis in the United Kingdom.

DR2 frequency. Confidence limits for estimates of prevalence have previously been calculated ${ }^{1}$ and we have used the same method to provide limits for the more recent studies.

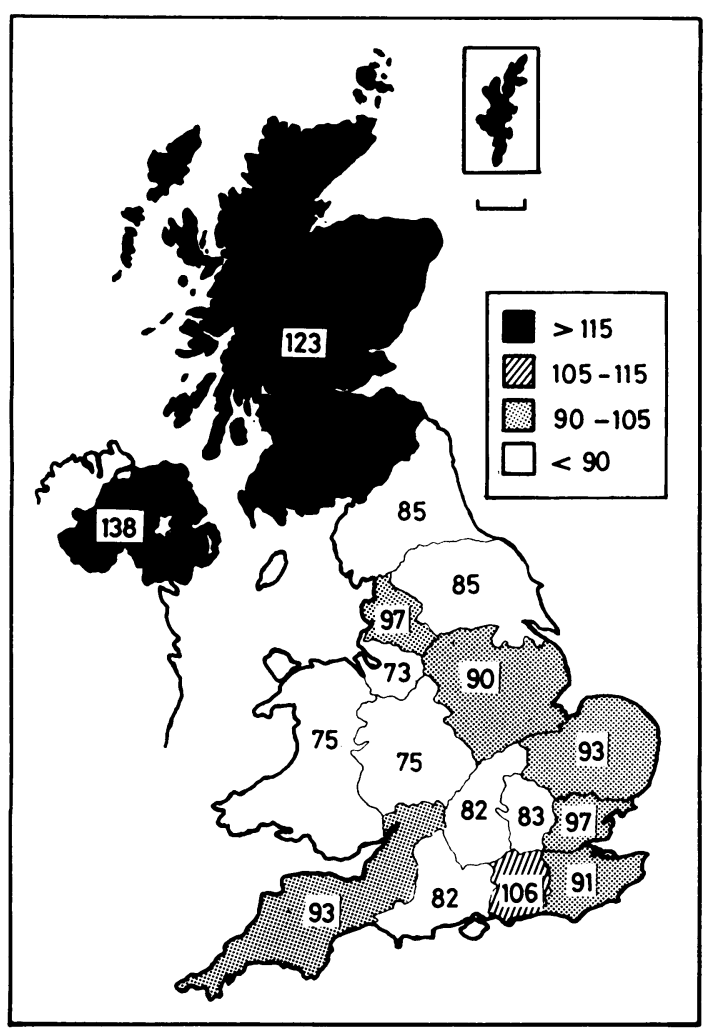

Fig 4 Standardised Mortality Ratios for multiple sclerosis in Scotland, Northern Ireland, Wales and the Regional Health Authorities of England.

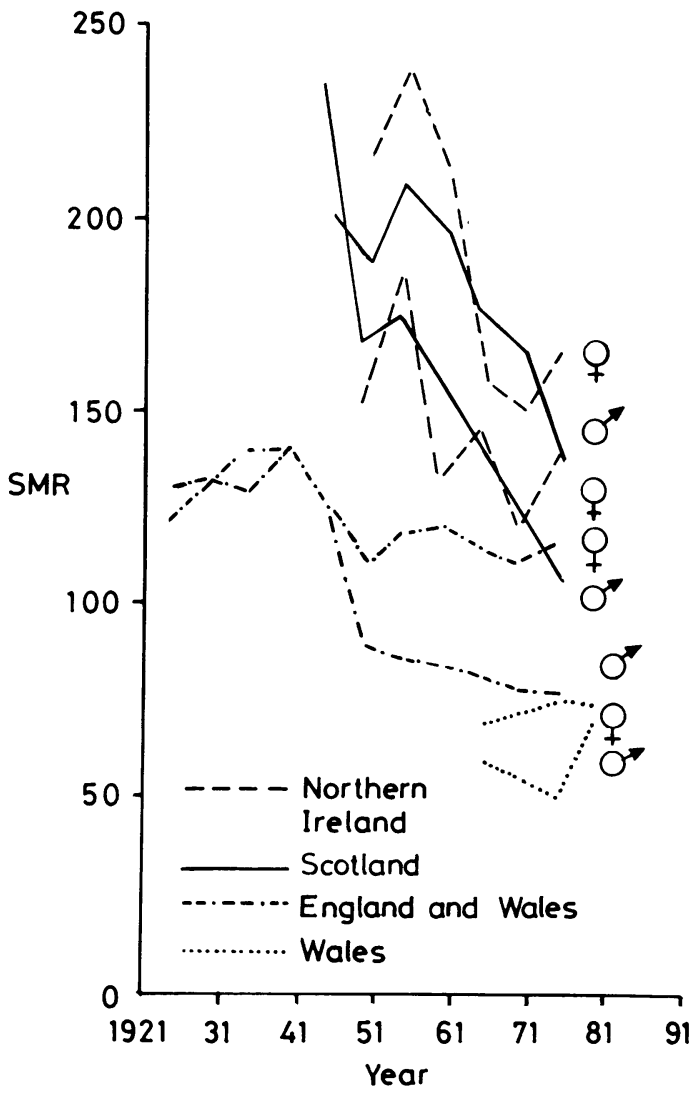

Fig 5 Serial estimates of Standardised Mortality Ratio throughout the United Kingdom between 1921-80.

\section{Results}

Incidence

Figure 1 shows the incidence of multiple sclerosis from individual studies in the United Kingdom since $1940 .^{38-17}$ The incidence in the Orkneys has been the highest reported in the world $\left(10 \cdot 5 / 10^{5} / \mathrm{yr}\right.$ between 1941-64) but has fallen $\left(3 \cdot 7 / 10^{5} /\right.$ year between 1965-82) below the level originally found in Aberdeen (5.3/10 $/$ year from $1959-73)$, where a recent rise $\left(7 \cdot 5 / 10^{5} /\right.$ year between $\left.1974-80\right)$ has been observed, and Northern Ireland $\left(4 \cdot 8 / 10^{5} /\right.$ year in 1961). Incidence rates in England are the lowest in the United Kingdom $\left(2 \cdot 4-4 / 10^{5} /\right.$ year $)$ but serial studies have not been performed. Rates for Wales are being determined.

\section{Prevalence}

Figure 2 shows the prevalence of multiple sclerosis in studies performed in the United Kingdom since 1931. ${ }^{37-24}$ The Orkney Islands have had the highest 


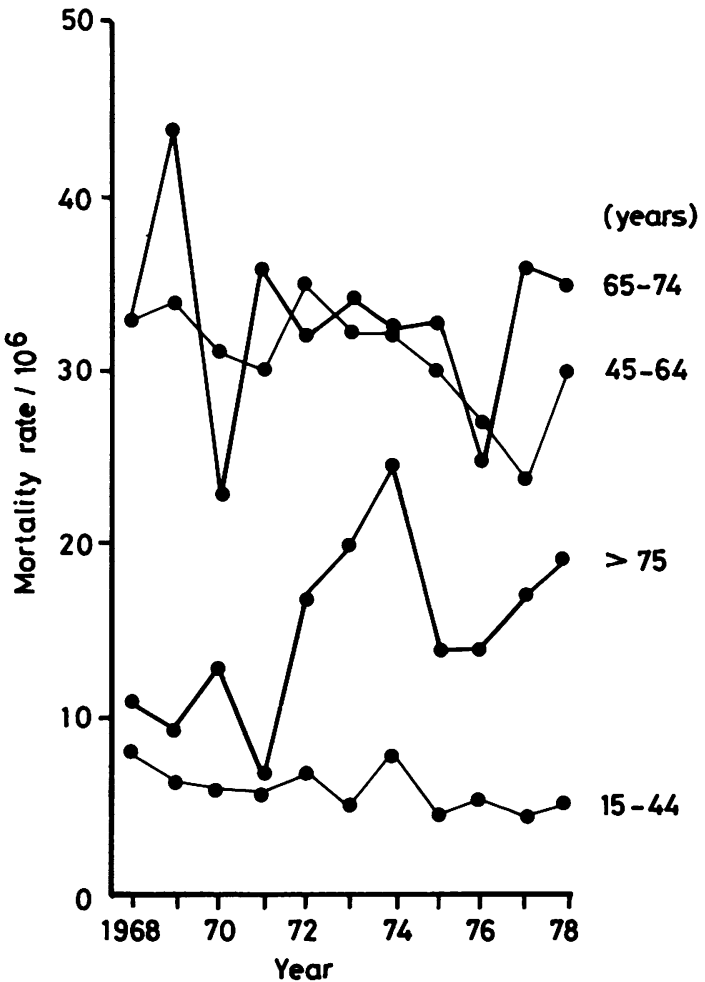

Fig 6 Male age-specific mortality rates in four age groups for England and Wales from 1968-1978.

recorded prevalence rate in the world $\left(258 / 10^{5}\right.$, definite and probable cases, $309 / 10^{5}$ including suspected cases) but this is now beginning to fall (193 \& $224 / 10^{5}$, respectively). The prevalence is high $\left(>30 / 10^{5}\right)$ in all regions of the United Kingdom studied since 1954 (ranging from $44-309 / 10^{5}$ ) and is increasing in each area which has been reinvestigated (fig 3). This may be a true increase or related to changes in methods of ascertainment.

\section{Mortality}

Figure 4 shows differences in SMRs for multiple sclerosis as the underlying cause of death throughout the United Kingdom aggregated for 1976-80.25-27 Scotland (123) and Northern Ireland (138) have amongst the highest rates in the world. Wales (75) has a rate consistently below the average for 1951-75 in England and Wales on which these rates are standardised, despite our recent high estimate of prevalence (c. 113/105: unpublished observations). The observed numbers of deaths are significantly different from those expected $\left(\mathrm{X}^{2}{ }_{15}=29.4 ; \mathrm{p}<0.05\right)$. The rates have been compared between males and females

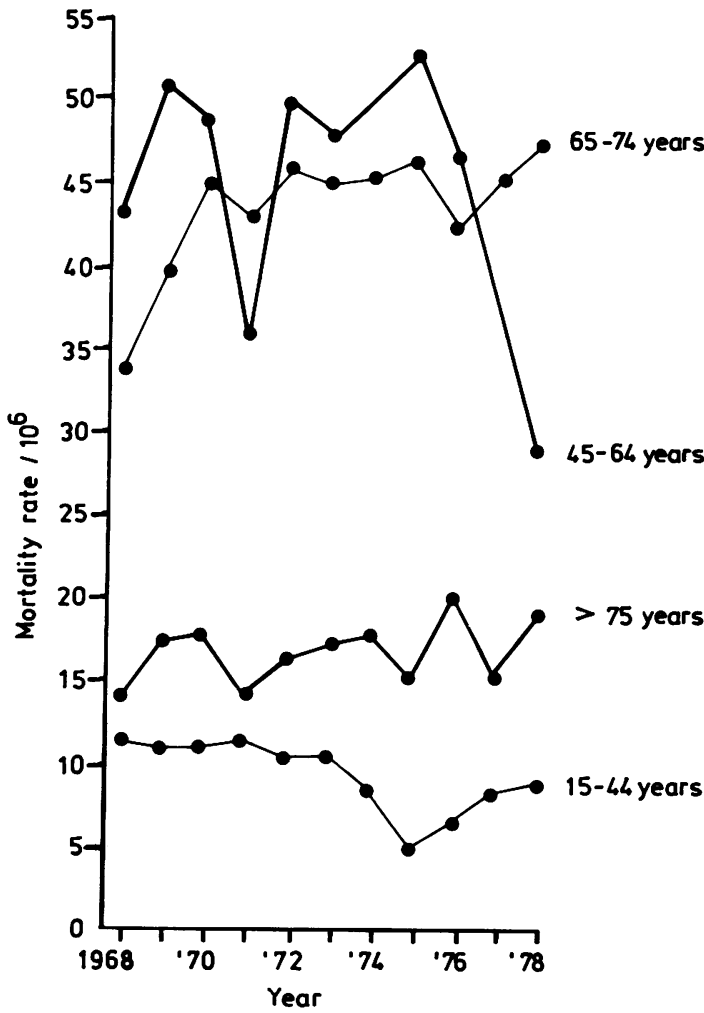

Fig 7 Female age-specific mortality rates for four age groups for England and Wales from 1968-78.

for each country in the United Kingdom for quinquennia from $1921-75^{4}$ (fig 5). There is a significant decline in mortality for males and females in England ( $p<0.002$ and $<0.02$ respectively) and Scotland ( $p$ $<0.01$ and $<0.05$ ). Age-specific rates are shown in figs $6 \& 7$ and are only available for England and Wales. ${ }^{28}$ A significant decline has occurred in mortality for males aged 45-64 years $(p<0.05)$ and females aged 15-44 years $(p<0.01)$. Although rates are increasing in older age groups these trends are not significant. Rates for females are higher than males.

\section{Hospital discharges}

Hospital discharge rates in the $\mathrm{UK}^{29}$ are shown in fig 8. There are significant regional variations $\left(\mathrm{X}^{2}{ }_{14}=\right.$ 506.4; $p<0.0005)$ and the discharge rates for each region correlate well with mortality $(r=0.900 p<$ 0.001 ). However, in England the observed trends demonstrate higher rates in the South East not correlating with incidence or prevalence which is higher in the North of England and this discrepancy may reflect higher readmission rates in the South East. Figure 9 shows a significant increase in hospital dis- 


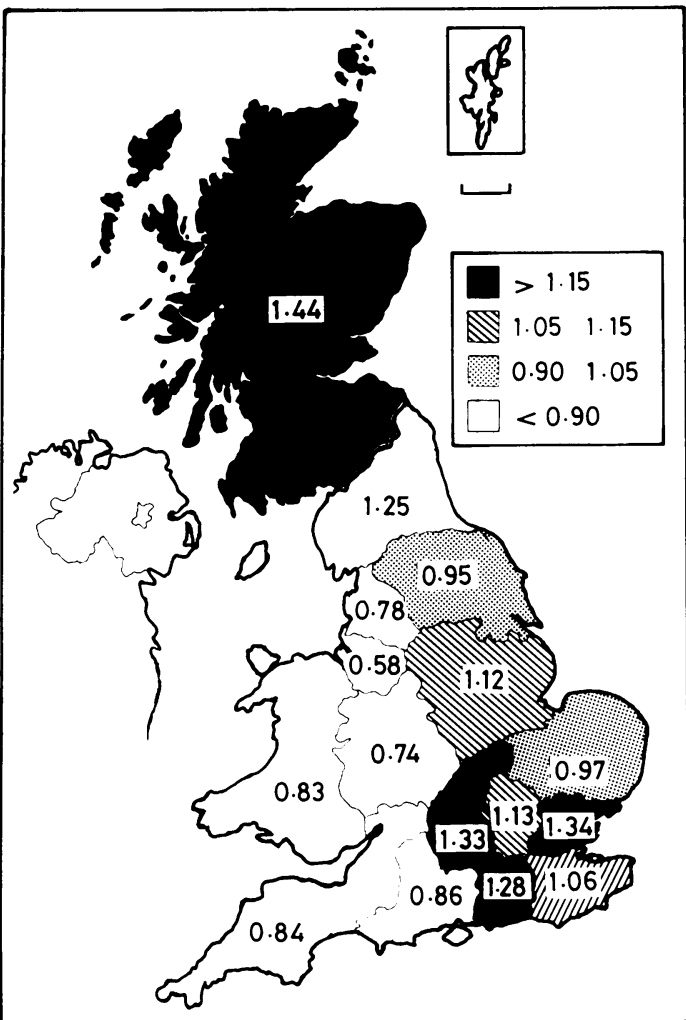

Fig 8 Mean proportional hospital discharge rates for multiple sclerosis in Scotland, Wales and the Regional Health Authorities of England.

charge rates for males $(\mathrm{p}<0.05)$ and females $(\mathrm{p}<$ 0.01 ) throughout England and Wales between $1968-78 .^{30}$

$G P$ patient consultation rates

Male and female patient consultation rates for multiple sclerosis recorded in the first and second National Morbidity Studies ${ }^{5}$ were $50 / 10^{5}, 70 / 10^{5}, 40 / 10^{5}$ and $80 / 10^{5}$ respectively. It has been claimed that regional variations in patient consultation rates from the first study show a gradient with higher rates in the east than west ${ }^{5}$ (data not shown in figures). Observations from the second study have previously been used to derive incidence rates for multiple sclerosis of $10 / 10^{5}$, year for males and $20 / 10^{5}$ year for females but the method of derivation is complex depending more on the number of episodes than new cases identified.

\section{HLA studies}

Figure 10 demonstrates the relationship between regional differences in the frequency of HLA-DR2 in normal individuals and the prevalence of multiple

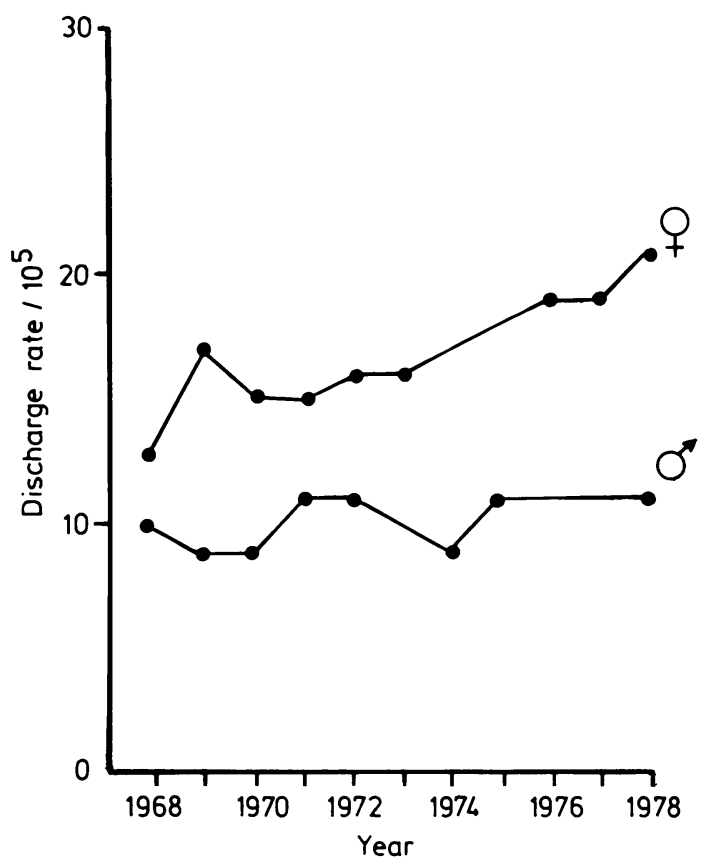

Fig 9 Hospital discharge rates for multiple sclerosis in England and Wales from 1968-1978.

sclerosis $(r=0.935, p<0.001)$. The frequency of HLA-DR2 does not differ significantly in population studies of patients with multiple sclerosis within the United Kingdom (fig 11). Since the frequency of HLA-DR2 varies in controls but not patients the

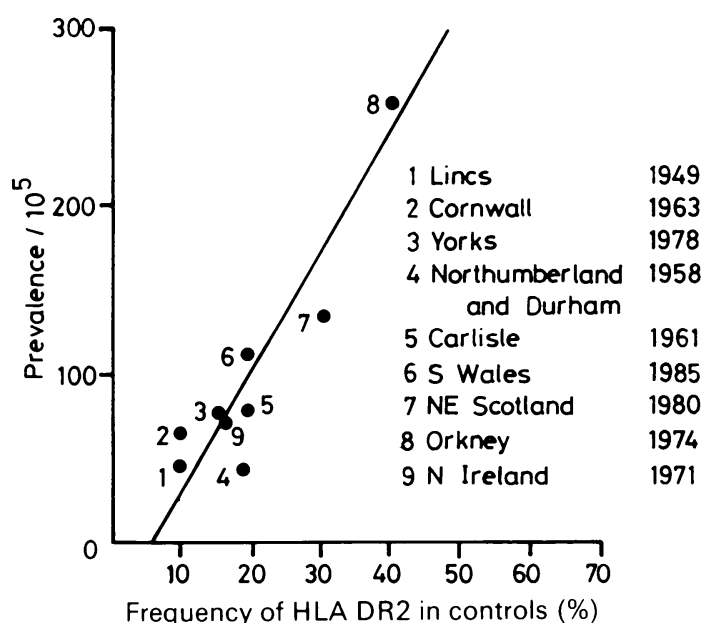

Fig 10 Regional differences in prevalence of multiple sclerosis and the frequency of $H L A-D R 2$ in controls throughout the United Kingdom. 


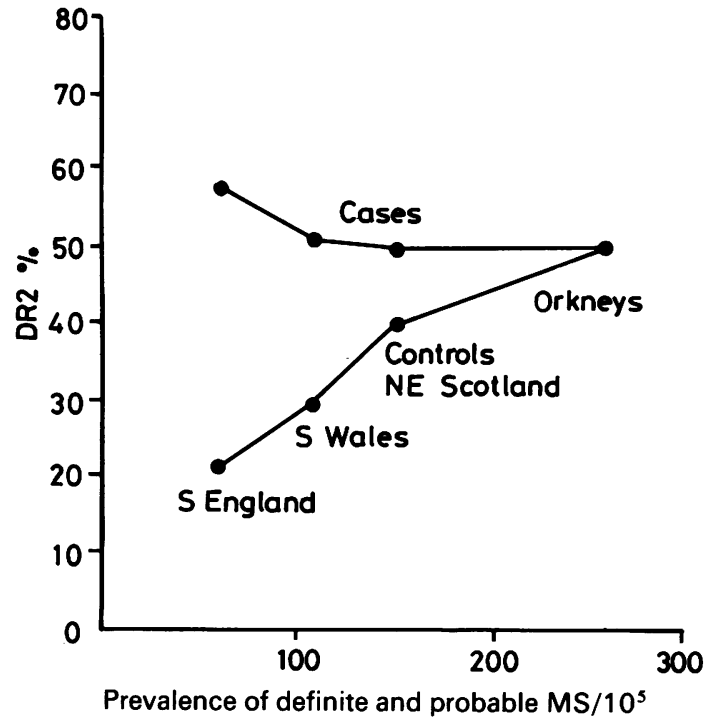

Fig 11 The prevalence of multiple sclerosis and the frequency of $H L A-D R 2$ in cases and controls at four sites in the United Kingdom.

strength of the association declines progressively in South East England ${ }^{31}$ \& Wales (unpublished observations) and is not seen in North East Scotland ${ }^{33}$ and the Orkneys. ${ }^{733}$

\section{Discussion}

There are geographical and temporal trends in the distribution of multiple sclerosis throughout the United Kingdom. Incidence, prevalence, mortality and hospital discharge rates indicate a gradient in the frequency of the disease between Southern England, Northern England, Northern Ireland, Wales, Scotland and the Orkneys. However incidence and prevalence are falling in the Orkney Islands which previously have had the highest rates in the world. The possibility exists that all these findings merely reflect variations in methods used to collect information.

If the frequency of a disease is static in one population, the incidence and mortality should be the same, and the prevalence should be equal to the product of either rate and duration of the disease. Rates are influenced by age and sex structure within a population and should be standardised, as is usually only done for mortality. Since there is no diagnostic test for multiple sclerosis, case ascertainment is dependent on recognition by medical practitioners. Local awareness and facilities for supplementing diagnosis with laboratory tests will influence incidence, prevalence, mortality and morbidity statistics. Categories of patient who may be unrecognised or deliberately excluded from surveys include those with isolated demyelinating lesions or benign cases with a very long interval between episodes; it has been estimated that up to $20 \%$ of cases are not recognised at all during life. ${ }^{35}$ The degree of underdiagnosis can be inferred from surveys in Winnipeg and the Shetland and Orkney Isles where the prevalence rose in a second assessment by $33 \%$ \& $50 \%$ respectively. ${ }^{2235}$ False positive diagnoses can also contaminate individual studies. ${ }^{22}$ Certification errors, especially for mortality of chronic diseases such as multiple sclerosis in which complications are the registered cause of death, can cause underestimation of mortality by up to $50 \% .^{36}$ Changes in requirements for registering causes of death, and elimination of ambiguities in nomenclature have lead to an apparent fall in mortality rates for multiple sclerosis of $12 \& 18 \%$ respectively in some parts of the world. ${ }^{37}$

Hospital discharge rates reflect the number of admissions, not patients, and show marked geographical variations or fluctuations with time in a single area depending on the availability of services and fashions in management; errors in coding and processing are probably low. General Practice surveys of patient consultation rates have been standardised for several conditions but not multiple sclerosis; since $95 \%$ of patients consult their general practitioner in a three year period these surveys could avoid the selection bias inherent in hospital based surveys, and approximate to a true prevalence study rather than the present case finding exercises.

But methodology has been consistent within and between some areas where marked differences in the distribution of multiple sclerosis exist and the trends are not entirely artefactual. Mortality rates are lowest in Wales and gradually increase in England, Scotland, Northern Ireland and the Orkneys. Overall, mortality rates have declined since 1921, particularly during and immediately after World War $2 .{ }^{38}$ But agespecific rates show that the reduction is most marked in younger age groups and consequently there is now an increase in death rate amongst individuals aged 70 and above due to better survival. The drop in mortality can in part account for the increase in prevalence seen in most areas studied serially. Hospital discharges attributed to multiple sclerosis have increased significantly for males and females in England and Wales since 1968; it is unlikely that this can be explained by a change in readmission rates over this decade and these data probably reflect a true increase in prevalence attributable to better survival but not necessarily increased incidence. It has been shown that corrected morality rate can be used accurately to predict prevalence. ${ }^{36}$ Since mortality is com- 
parable in Northern Ireland and North East Scotland, it is probable that the prevalence for Northern Ireland is an underestimate. Conversely the low mortality rate in Wales compared with the remainder of the United Kingdom may be due both to undercertification of multiple sclerosis in mortality returns from Wales and underestimation of prevalence in England \& Northern Ireland.

From an overall analysis of these statistics the incidence of multiple sclerosis appears to vary within the United Kingdom being lowest in Southern England and progressively higher in Northern England, Northern Ireland, Wales, mainland Scotland and the Orkneys. The incidence seems to be declining in the Orkney Islands and a similar decline has been observed in Denmark, The Faeroes and Iceland ${ }^{2} 39$ which may be heralding an overall fall in the incidence of the disease.

The geographical distribution of multiple sclerosis correlates with the frequency of HLA-DR2 in normal individuals from different parts of the United Kingdom. We have fitted a regression line to this data but this should be interpreted with caution. Although there is no information relating to points at the lower end of the line in the United Kingdom the association persists for many low prevalence areas elsewhere in the world; but there are notable exceptions such as Hungarian Gypsies in whom the normal frequency of HLA-DR2 is high but prevalence for multiple sclerosis is low. ${ }^{40}$ The estimates of prevalence that we have plotted may be spuriously low in Southern England, Northumberland and Northern Ireland; HLA-DR2 frequencies are not available for certain localities and the nearest possible estimate has been used in each case. However the relationship between multiple sclerosis and HLA-DR2 is still observed if the remaining points $(2,3,5,6,7$ and 8$)$ are considered. The figures from the Orkney Islands (8) make a disproportionate contribution to the $r$ value quoted. Although we have assumed that the frequency of HLA-DR2 in Orcadians is similar to that of the locally designated antigen B-group 4, it may be lower in which case this point would lie further to the left. When these factors are taken into consideration the relationship is curvilinear, with a shallow gradient near the origin gradually becoming steeper in areas where HLA-DR2 is common. Points for the United Kingdom lie on the steep part of the curve where the relationship remains linear.

The hypothesis that histocompatibility genes in some way determine the distribution of multiple sclerosis cannot easily explain the decline in incidence in the Orkneys and elsewhere, or the lack of an association between HLA-DR2 and multiple sclerosis in North East Scotland and the Orkneys. The change in incidence in multiple sclerosis in some areas pre- sumably reflects decline in exogenous aetiological agents. Specifically it has been suggested that canine distemper virus has been responsible for a prolonged epidemic of the disease in the Orkneys and some other islands. ${ }^{23}$ Evidence from migration studies does suggest that an exogenous agent acquired in childhood is important in the aetiology of multiple sclerosis but there is no clear evidence favouring a particular organism.

The absence of HLA-DR2 association in parts of Scotland may be explained in several ways. First, multiple sclerosis as presently defined may be the expression of more than one disease and this could account for the genetic heterogeneity. Secondly, HLA-DR2 may merely be a marker of a population susceptibility to multiple sclerosis and the lack of association in Northern parts of the United Kingdom could occur because other as yet unidentified genes, not necessarily HLA linked, are of equal or more importance in the pathogenesis. Combined genotypic and phenotypic analysis does reveal stronger disease associations than are seen with HLA-DR2 alone ${ }^{41}$ and the more recently identified HLA-D region alleles, especially HLA-DQw1, appear also to show stronger associations; ${ }^{32}$ however this allele may be identical to locally designated antigens, including B group 4, previously associated with multiple sclerosis. ${ }^{742}$ Thirdly, the associations observed in patients with multiple sclerosis in some regions could have been biased by sampling errors thereby accounting for the reported geographical differences in association between the HLA system and multiple sclerosis.

But we favour an alternative explanation. The aetiology of the disease is likely to be multifactorial and require possession of susceptibility genes, exposure to environmental agents, possibly at critical times, ${ }^{2}$ and other trigger factors. Individually these are neither sufficient nor essential for the pathogenesis, but the disease develops when they occur in the same individual. Any factor which is common in a given population will be present in many unaffected individuals and not necessarily associated with the disease. Under these circumstances frequency will increase because the probability of concurrence of the remaining critical events is high; conversely when each aetiological factor is infrequent the chance of them all occurring in the same individual and therefore incidence of the disease are both lower. If a high proportion of the population possess the susceptibility gene(s) and only some are exposed to the exogenous agent(s) the distribution will be determined by environmental factors alone. If all are exposed to the exogenous agent(s) and only some possess the susceptibility gene(s) the pattern of the disease within a population will be governed more by genetic factors. In areas where possession of the gene 
and exposure to the agent are both common other factors, such as age of exposure, will be of importance in determining the local distribution. Although previous analysis of multiple sclerosis in the Orkneys has suggested that the disease is polygenic and that the overall genetic contribution is moderate,${ }^{43}$ we suggest that, in association with other genetic and environmental factors that remain to be identified histocompatibility genes have a significant role in determining the distribution of multiple sclerosis throughout the United Kingdom.

We are grateful to Miss A Stratton, Mr P Learoyd, Dr D Middleton, Dr C Darke and Mr M Boyce for providing the frequencies of HLA-DR2 in normal controls and to the Welsh Office and the Office of Population Censuses and Surveys for providing mortality statistics for Wales.

\section{References}

${ }^{1}$ Kurtzke JF. A Reassessment of the Distribution of Multiple Sclerosis. Parts 1 \& 2. Acta Neurol Scand 1975;51:110-57.

${ }^{2}$ Acheson ED. In: Matthews WB, Acheson ED, Batchelor JR, Weller RO, eds. McAlpine's Multiple Sclerosis. London: Churchill Livingstone, 1985:3-46.

${ }^{3}$ Cook SD, Cromarty MB, Tapp W, Poskanser D, Walker JD, Dowling PC. Declining Incidence of Multiple Sclerosis in the Orkney Islands. Neurology (Cleveland) 1985;35:545-51.

${ }^{4}$ Alderson M. International Mortality Statistics. London: Macmillan, 1983:524.

${ }^{5}$ Watts CAH in: General Register Office. Morbidity Statistics From General Practice 1955/56 (Vols. I-III). Studies on Medical and Population Subjects Number 14. London: HMSO, 1958:53-66.

${ }^{6}$ Royal College of General Practitioners, Office of Population Censuses and Surveys, Department of Health and Social Security. Morbidity Statistics From General Practice, Second National Study. Studies on Medical and population Subjects Number 26. London: HMSO, 1974:211.

${ }^{7}$ Poskanser DC, Terasaki PI, Prenney LB, Sheridan JL, Park MS. Multiple Sclerosis in the Orkney and Shetland Islands III: Histocompatibility determinants. $J$ Epidemiol Community Health 1980;34:253-7.

${ }^{8}$ Pratt RTC. The Familial Occurrence of Disseminated Sclerosis. Annals of Eugenics. 1951;16:45-59.

${ }^{9}$ Allison RS, Millar JHD. Prevalence and Familial Incidence of Disseminated Sclerosis (A Report to the Northern Ireland Hospitals Authority on the results of a Three-Year Survey). Prevalence of Disseminated Sclerosis in Northern Ireland. Ulster Med J 1954;23 (Suppl No. 2):5-27.

${ }^{10}$ Sutherland JM. Observations on the Prevalence of Multiple Sclerosis in Northern Scotland. Brain 1956;79:635-54.

${ }^{11}$ Hargreaves ER. Epidemiological Studies in Cornwall. Proc $R$ Soc Med 1969;54:209-16.

12 Poskanser DC, Schapira K, Miller H. Epidemiology of
Multiple Sclerosis in the Counties of Northumberland and Durham. J Neurol Neurosurg Psychiatry 1963;26:368-76.

${ }^{13}$ Brewis M, Poskanser DC, Rolland C, Miller H. Neurological Disease in an English City. Acta Neurol Scand (Suppl) 1966;42 (Suppl 24):1-89.

${ }^{14}$ Millar JHD, Allison RS. Multiple Sclerosis, a Disease Acquired in Childhood. Springfield: CC Thomas, 1971:98.

${ }^{15}$ Shepherd DI, Downie AW. Prevalence of Multiple Sclerosis in North-East Scotland 1978;2:314-6.

${ }^{16}$ Shepherd DI, Downie AW. A further Prevalence Study of Multiple Sclerosis in north-east Scotland. J Neurol Neurosurg Psychiatry 1980;43:310-5.

${ }^{17}$ Downie AW, Phadke JG. The Chief Scientist Reports ... Multiple Sclerosis in North East Scotland. Health Bulletin (Edinb) 1983;42(3):151-6.

${ }^{18}$ Allison RS. Disseminated Sclerosis in North Wales. Brain 1931;53(4):391-430.

${ }^{19}$ Campbell AMG, Herdan G, Tatlow WFT, Whittle EG. Lead in Relation to Multiple Sclerosis. Brain 1951;73:52-69.

${ }^{20}$ Allison RS. Some Neurological Aspects of Medical Geography. Proc $R$ Soc Med 1963;56:71-6.

${ }^{21}$ Fog M, Hyllested K. Prevalence of Disseminated Sclerosis in the Faroes, the Orkneys and Shetland. Acta Neurol Scand (Suppl) 1966;42 (suppl 19):9-11.

${ }^{22}$ Poskanser DC, Prenney LB, Sheridan JL, Yonkondy J. Multiple Sclerosis in the Orkney and Shetland Islands. J Epidemiol Community Health 1980;34:229-39.

${ }^{23}$ McCoubrie M, Shuttleworth D. Prevalence of Multiple Sclerosis in West Yorkshire. Br Med J 1978;2:570.

${ }^{24}$ Dean G, Goodall J, Downie A. The Prevalence of Multiple Sclerosis in the Outer Hebrides Compared with North-East Scotland and the Orkney and Shetland Islands. J Epidemiol Community Health 1981;35:110-3.

${ }^{25}$ Office of Population Censuses and Surveys. Mortality Statistics: Area: England and Wales. London: HMSO, 1974-83 (Series DH5 Nos 1-10), 1976-84.

${ }^{26}$ General Register Office (Scotland). The Registrar Generals Annual Reports 1976-80. Edinburgh: HMSO, 1977-82.

${ }^{27}$ General Register Office (Northern Ireland). The Registrar Generals Annual Reports 1976-80. Belfast: HMSO, 1978-82.

${ }^{28}$ Office of Population Censuses and Surveys. Mortality Surveillance 1968-78: England and Wales. London: HMSO, 1980:177.

${ }^{29}$ Office of Population Censuses and Surveys. The Hospital Inpatients Enquiry. London: HMSO, 1974-83. Series MB4 Nos 2-23. 1978-85.

${ }^{30}$ Department of Health and Social Security, Office of Population Censuses and Surveys, Welsh Office. Trends in Morbidity 1968-78: applying surveillance techniques to the Hospital In-patient enquiry: England and Wales. Fareham: HMSO, 1981.

${ }^{31}$ Fielder AHL, Batchelor JR, Nason Vakarelis B, Compston DAS, McDonald WI. Optic Neuritis and Multiple Sclerosis: Do Factor B Alleles Influence Progression of Disease? Lancet 1981;ii:1246-8.

${ }^{32}$ Francis DA, Batchelor JR, McDonald WI, Hern JEC, Downie AW. Multiple Sclerosis and HLA-DQw1. Lan- 
cet 1986;i:211.

${ }^{33}$ Compston DAS. Multiple Sclerosis in the Orkneys. Lancet 1981;ii:98.

${ }^{34}$ McKay RP, Hirano A. Forms of Benign Multiple Sclerosis. A Report of Two Clinically Silent Cases Discovered at Autopsy. Arch Neurol 1967;17:588-600.

${ }^{35}$ Stazio A, Kurland LT, Bell LG, Saunders MG, Rogot E. Multiple Sclerosis in Winnipeg, Manitoba: Methodological Considerations of Epidemiological Survey. $J$ Chronic Dis 1964;17:415-38.

${ }^{36}$ Shepherd DI. Multiple Sclerosis in North East Scotland. MD Thesis, 1976. University of Aberdeen.

${ }^{37}$ McAlpine D, Compston ND, Lumsden CE. Multiple Sclerosis. London: Livingstone, 1955:304.

${ }^{38}$ Stocks P. Multiple Sclerosis Distribution in England and Wales and parts of Europe. Journal of Hygiene (Camb.) 1971;69(3):373-89.

${ }^{39}$ Kurtzke JF, Gudmunsson JR, Bergmann S. Multiple
Sclerosis in Iceland: 1. Evidence of a Post-War Epidemic. Neurology (Cleveland) 1983;32:143-50.

${ }^{40}$ Palffy G. Multiple Sclerosis in Hungary, including the Gipsy Population In: Kuroiwa Y, Kurland LT, eds. Multiple Sclerosis East and West. Basel:Karger 1982:149-58.

${ }^{41}$ Cohen D, Cohen O, Marcadet A, et al, Class II HLA-DC Beta-chain DNA Restriction Fragments Differentiate Among HLA-DR2 Individuals in Insulin-dependent Diabetes and Multiple Sclerosis. Proc Natl Acad Sci USA 1984;81:1774-8.

${ }^{42}$ Compston DAS, Batchelor JR, McDonald WI. BLymphocyte Alloantigens Associated with Multiple Sclerosis. Lancet 1976;ii:1261-5.

${ }^{43}$ Roberts DF, Roberts MJ, Poskanser DC. Genetic Analysis of Multiple Sclerosis in Orkney. J Epidemiol Community Health 1979;33:229-35. 